\title{
DAdOS HEMATOLógICOS DA CAVALA, SCOMBEROMORUS CAVALLA (CUVIER), DO NORDESTE BRASILEIRO
}

\author{
MARIA DA SILVA PITOMBEIRA \\ FRANCISCA VÂNIA BARRETO GOMES \\ JOSÉ MURILO MARTINS
}

Laboratório de Ciências do Mar e Faculdade de Medicina da Universidade Federal do Ceará - Fortaleza - Ceará - Brasil.

\section{SUMĀRIO}

Os autores apresentam alguns dados hematológicos da cavala, Scomberomorus cavalla (Cuvier), das águas costeiras do nordeste brasileiro.

Expressos em valores médios, os principais resultados obtidos são os seguintes: eritrócitos $=3.910 .800 / \mathrm{mm}^{3}$, hemoglobina $=10,9 \mathrm{~g} \%$, hematócrito $=49 \%$, leucócitos totais $=31.392 / \mathrm{mm}^{3}$ e trombócitos $=$ 11.054/ $\mathrm{mm}^{3}$. A fórmula leucocitária mostra-se assim distribuída, linfócitos $=78,7 \%$, monócitos $=10,8 \%$, neutrófilos $=10,4 \%$ e eosinófilos $=0,1 \%$. Foi realizado o estudo morfológico e citoquímico dos diversos elementos celulares.

Os resultados obtidos foram comparados com outros relativos à mesma espécie, da costa atlântica dos Estados Unidos da América. Igualmente, foram feitas comparações com dados hematológicos da serra, Scomberomorus maculatus (Mitchill), tanto do nordeste brasileiro como da outra área geográfica acima referida.

HEMATOLOGICAL DATA ON THE KING MACKEREL, SCOMBEROMORUS CAVALLA (CUVIER), FROIM COASTAL NORTHEAST BRAZILIAN WATERS

\section{SUMMARY}

The main results obtained, presented in mean values, are the following: erythrocytes $=3,910,800 / \mathrm{mm}^{3}$, hemoglobin $=10.9 \mathrm{~g} \%$, hematocrit $=49 \%$, total leucocytes $=31,392 / \mathrm{mm}^{3}$ and thrombocytes $=$ $11,054 / \mathrm{mm}^{3}$. The leucocyte formule is thus distributed, lymphocytes $=78.7 \%$, monocytes $=10.8 \%$, neutrophyles $=10.4 \%$, and eosinophyles $=0.1 \%$. Morphofological and cytochemical studies of several celular elements were effected.

The obtained results are compared with those recorded for the same species from the Atlantic coast of the United States of America. They were also compared with hematological data on the Spanish mackerel, Scomberomorus maculatus (Mitchill), from the Brazilian Northeast as well as from the other geographical area above reffered.

Número especial em homenagem ao Prof. Dr. Paulo Sawaya, no ano jubilar de seu magistério. 
A cavala, Sccmberomorus cavalla (Cuvier), peixe pelágico costeiro, representa uma das espécies mais abundantes e de alto valor comercial no nordeste brasileiro.

A sua distribuição geográfica se estende desde o Golfo do Maine (U.S.A.) até o Rio de Janeiro (Brasil), incluindo-se todo o Golfo do México (Cervigón, 1966).

$\mathrm{Na}$ literatura ictiológica encontramos vários trabalhos relativos ao sangue de peixes da família Scombridae, mas apenas Engel \& Davis (1964) fazem referência aos valores de eritrócitos e hemoglobina da espécie mencionada.

O presente trabalho é uma contribuição ao conhecimento de alguns valores hematológicos da cavala da costa nordeste do Brasil.

\section{MATERIAL E MÉTODOS}

Estudamos amostras do sangue de 25 exemplares da cavala, capturados a cerca de 6 milhas da costa, em frente ao município de Fortaleza (Ceará - Brasil).

O sangue foi colhido ao nível dos vasos branquiais, apresentando os peixes todos os sinais de vitalidade. Foi usada a heparina como anticoagulante, sendo desprezadas as amostras com sinais evidentes de hemólise ou coágulos. O comprimento zoológico (folk length) de cada peixe foi anotado, não se identificando o sexo.

As amostras do sangue foram coletadas logo após a captura dos peixes, conservadas em cubas isotérmicas contendo gelo, sendo então encaminhadas ao laboratório. O tempo transcorrido entre a coleta e o início dos exames variou de 6 a 8 horas.

A contagem dos eritrócitos foi efetuada na câmara de Neubauer, usando o líquido de Hayem como diluente; a dosagem da hemoglobina foi feita pelo método de Sahli e a determinação do valor globular pelo hematócrito de Wintrobe.

A contagem total dos leucócitos e trombócitos foi realizada pelo método indireto de Fônio, e a fórmula diferencial leucocitária foi determinada em esfregaço de sangue corado pelos corantes de MayGrünwald e Giemsa, procedendo-se a identificação morfológica de 200 células. 
Para estudo do conteúdo de substâncias mucopolissacárides nos leucócitos foi efetuada a reação do PAS em esfregaços de sangue, segundo a técnica de McManus (1946), modificada por Hayhoe (1964).

Para as medidas dos diâmetros celulares foi utilizada uma ocular micrométrica (6X), objetiva de imersão (90X) e um fator de correção previamente determinado, igual a 1,63.

\section{RESULTADOS}

O comprimento zoológico dos peixes estudados variou de 21,2 a $72,8 \mathrm{~cm}$ com uma média de $45,9 \mathrm{~cm}$, sendo de $14,2 \mathrm{~cm}$ o desvio padrão.

Os valores da série vermelha apresentaram os seguintes resultados: eritrócitos - de 2.530 .000 a 5000.000 , com uma média de $3.910 .800 / \mathrm{mm}^{3}$; hemoglobina — de 8,0 a 13,8 , com um valor médio de 10,9 g\%; hematócrito — de 34 a 60, com uma média de $49 \%$. O desvio padrão e o coeficiente de variação de cada série de valores estão na tabela $\mathrm{I}$.

TABELA I

Dados hematológicos da série vermelha da cavala, Scomberomorus cavalla (Cuvier), do nordeste brasileiro

\begin{tabular}{l|c|c|c|c|c}
\hline Determinações & $\begin{array}{c}\text { Peixes } \\
(\mathrm{n})\end{array}$ & Variação & $\begin{array}{c}\text { Média } \\
\text { aritmética } \\
(\mathrm{x})\end{array}$ & $\begin{array}{c}\text { Desvio } \\
\text { padrão } \\
(\mathrm{s})\end{array}$ & $\begin{array}{c}\text { Coeficiente } \\
\text { de } \\
\text { variação } \\
\text { (C.V.) }\end{array}$ \\
\hline \hline $\begin{array}{l}\text { Eritrócitos } \\
\left(10^{6} / \mathrm{mm}^{3}\right)\end{array}$ & 25 & $2,53-5,00$ & 3,91 & 0,68 & 17,52 \\
$\begin{array}{c}\text { Hemoglobina } \\
(\mathrm{g} \%)\end{array}$ & 25 & $8,0-13,8$ & 10,90 & 1,57 & 14,40 \\
$\begin{array}{c}\text { Hematócrito } \\
(\%)\end{array}$ & 12 & $34-60$ & 49,33 & 7,30 & 14,80 \\
\hline
\end{tabular}

$\mathrm{Na}$ tabela II estão expressos os resultados encontrados para a série branca e trombócitos, com os respectivos desvios padrões e coeficientes de variação.

Os leucócitos totais tiveram uma variação de 8.433 a 78.690, com média de $31.392 / \mathrm{mm}^{3}$. Foram identificados 4 tipos de células da linhagem leucocitária: linfócitos — de 45,0 a 93,0\% (valores rela- 
TABELA II

Dados hematológicos da série branca e trombócitos da cavala, Scomberomorus cavalla (Cuvier), do nordeste brasileiro

\begin{tabular}{l|c|c|c|c|c|c}
\hline & Peixes & Variação & $\begin{array}{c}\text { Média } \\
\text { aritmé- } \\
\text { tica } \\
\text { Determinações }\end{array}$ & $\begin{array}{c}\text { Desvio } \\
\text { padrão } \\
\text { (s) }\end{array}$ & $\begin{array}{c}\text { Coefi- } \\
\text { ciente } \\
\text { de } \\
\text { variação } \\
\text { (C.V.) }\end{array}$ & $\%$ \\
\hline \hline $\begin{array}{l}\text { Leucócitos totais } \\
\left(10^{3} / \mathrm{mm}^{3}\right)\end{array}$ & 25 & $8,43-78,69$ & 31,39 & 17,7 & 56,40 & 100,0 \\
$\begin{array}{c}\text { Linfócitos } \\
\left(10^{3} / \mathrm{mm}^{3}\right)\end{array}$ & 25 & $7,16-73,18$ & 24,70 & 17,5 & 71,22 & 78,7 \\
$\begin{array}{c}\text { Monócitos } \\
\left(10^{3} / \mathrm{mm}^{3}\right)\end{array}$ & 25 & $0,56-6,16$ & 3,39 & 1,51 & 44,76 & 10,8 \\
$\begin{array}{c}\text { Neutrófilos } \\
\left(10^{3} / \mathrm{mm}^{3}\right)\end{array}$ & 25 & $0,41-9,14$ & 3,25 & 2,50 & 77,08 & 10,4 \\
$\begin{array}{c}\text { Eosinófilos } \\
\left(10^{3} / \mathrm{mm}^{3}\right)\end{array}$ & 25 & $0,00-0,44$ & 0,39 & 0,12 & 8,14 & 0,1 \\
$\begin{array}{c}\text { Trombócitos } \\
\left(10^{3} / \mathrm{mm}^{3}\right)\end{array}$ & 25 & $3,20-40,00$ & 11,05 & 7,48 & 67,68 & - \\
\hline
\end{tabular}

tivos) e de 7.168 a $73.182 / \mathrm{mm}^{3}$ (valores absolutos); monócitos de 3,0 a $21,0 \%$ (valores relativos) e de 560 a $6.163 / \mathrm{mm}^{3}$ (valores absolutos); neutrófilos - de 1,0 a $34,0 \%$ (valores relativos) e de 418 a $9.147 / \mathrm{mm}^{3}$ (valores absolutos); eosinófilos - de 0,0 a $2,0 \%$ (valores relativos) e de 0 a $448 / \mathrm{mm}^{3}$ (valores absolutos).

A fórmula leucocitária, para os 25 exemplares estudados, estabelecida sobre as médias dos valores absolutos, foi a seguinte: linfócitos $=78,7 \%$, monócitos $=10,8 \%$, neutrófilos $=10,4 \%$ e eosinófilos $=0,1 \%$.

Os trombócitos variaram de 3.200 a 40.000 , com um valor médio de $11.054 / \mathrm{mm}^{3}$

As correlações lineares estabelecidas entre o comprimento zoológico dos peixes e os resultados das determinações dos eritrócitos, hemoglobina, leucócitos e trombócitos não foram significativamente diferentes de zero, ao nível $\propto=0,05$. 


\section{Descrição das células do sangue}

(Figura 1)

Os eritrócitos da cavala são nucleados, elípticos, com núcleo central, acompanhando a forma da célula, apresentando cromatina compacta, sem nucléolos. O citoplasma é acidófilo, sendo observados, ocasionalmente, eritrócitos mais jovens com policromatofilia. Quando corados pela reação do PAS, são todos negativos.

Foram encontrados 4 tipos bem definidos de leucócitos: linfócitos, monócitos, neutrófilos e eosinófilos.

Os linfócitos são os menores elementos, têm forma arredondada, citoplasma escasso, basófilo, sem grãos; cromatina compacta, sem nucléolos. Quando corados pela reação do PAS, foram encontrados raros linfócitos com finos grãos PAS positivos, dispostos em coroa, e alguns com citoplasma levemente róseo; a maioria se apresentou PAS negativa.

Os monócitos são células de tamanho médio, de forma arredondada, tendo algumas contorno irregular. O citoplasma é levemente basófilo, às vezes contendo finas granulações azurófilas. $\mathrm{O}$ núcleo acompanha a forma da célula e frequentemente apresenta chanfradura; cromatina delicada, porém sem nucléolos. Quando submetidas à reação do PAS, estas células apresentam o citoplasma discretamente corado, com finos grãos positivos.

Os neutrófilos são os maiores elementos celulares do sangue da cavala. Apresentam citoplasma abundante, com finas e escassas granulações neutrofílicas; o núcleo é arredondado, excêntrico, apresentando cromatina em finos grumos, sem nucléolos. Frente à reação do PAS têm intensa positividade, sob a forma de pequenos grãos, enchendo todo citoplasma.

Os eosinófilos são células de tamanho médio, com forma arredondada e citoplasma abundante, contendo finos e escassos grãos eosinofílicos. O núcleo é excêntrico, redondo, com cromatina fina, sem nucléolos. Devido à escassez destes elementos não foi possível estudar o seu comportamento, quando corados pela reação do PAS.

Os trombócitos têm forma e tamanho muito variados - alongados, ovais ou arredondados. Em geral se dispõem em grupos, prin- 
cipalmente os de forma arredondada. O citoplasma é escasso, discretamente basófilo, sem granulações. O núcleo acompanha a forma da célula, com cromatina compacta e homogênea, sem nucléolos. Quando corados pela reação do PAS, mostram pequenos grãos positivos, localizados nos polos da célula.

$\mathrm{Na}$ tabela III são apresentadas as medidas dos diâmetros maior e menor das células e dos núcleos, de todos os elementos do sangue da cavala.

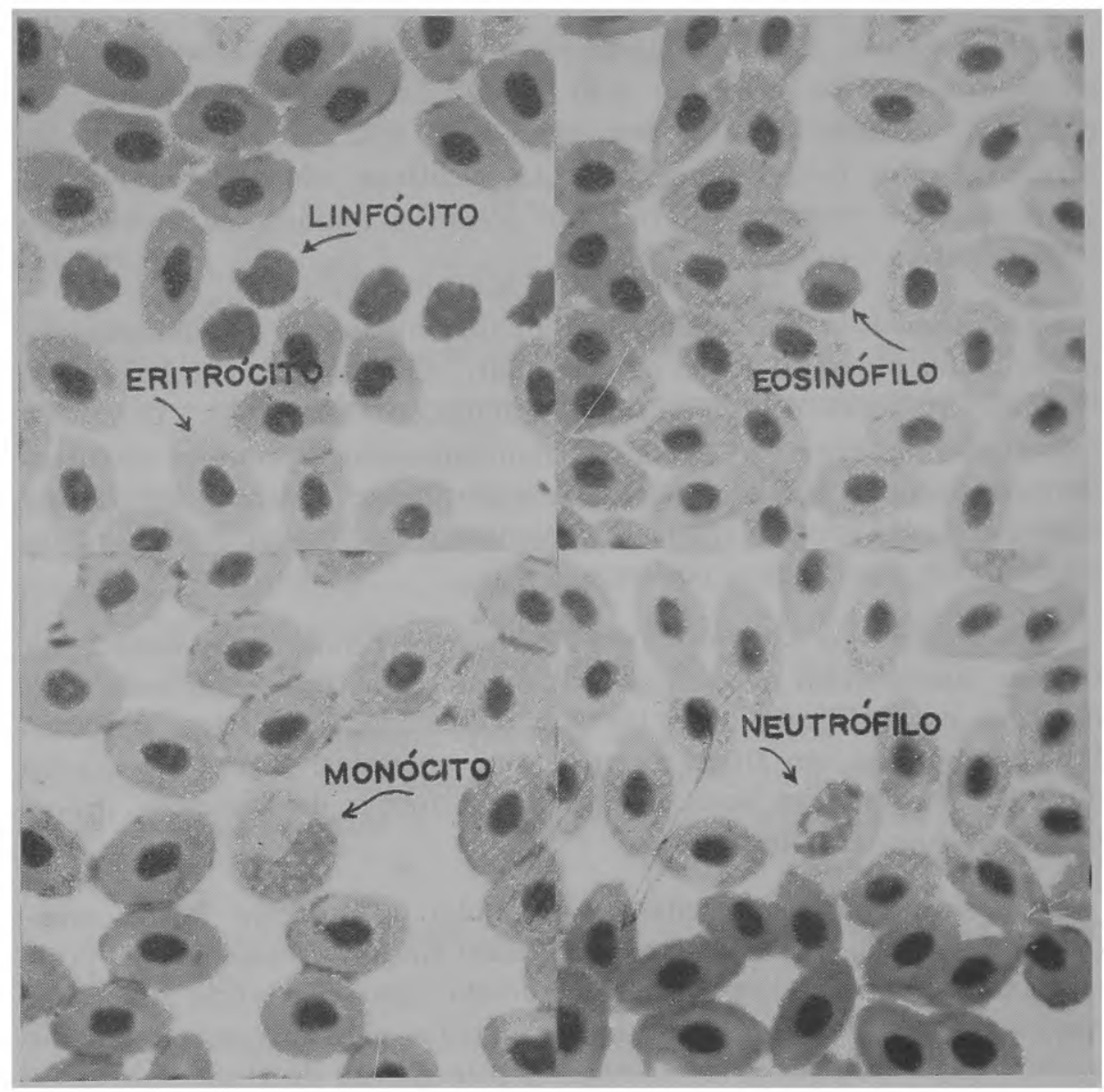

Figura 1 - Elementos celulares do sangue da cavala, Scomberomorus cavalla (Cuvier). 
TABELA III

Medidas dos diâmetros das células (micra) do sangue da cavala, Scomberomorus cavalla (Cuvier), do nordeste brasileiro.

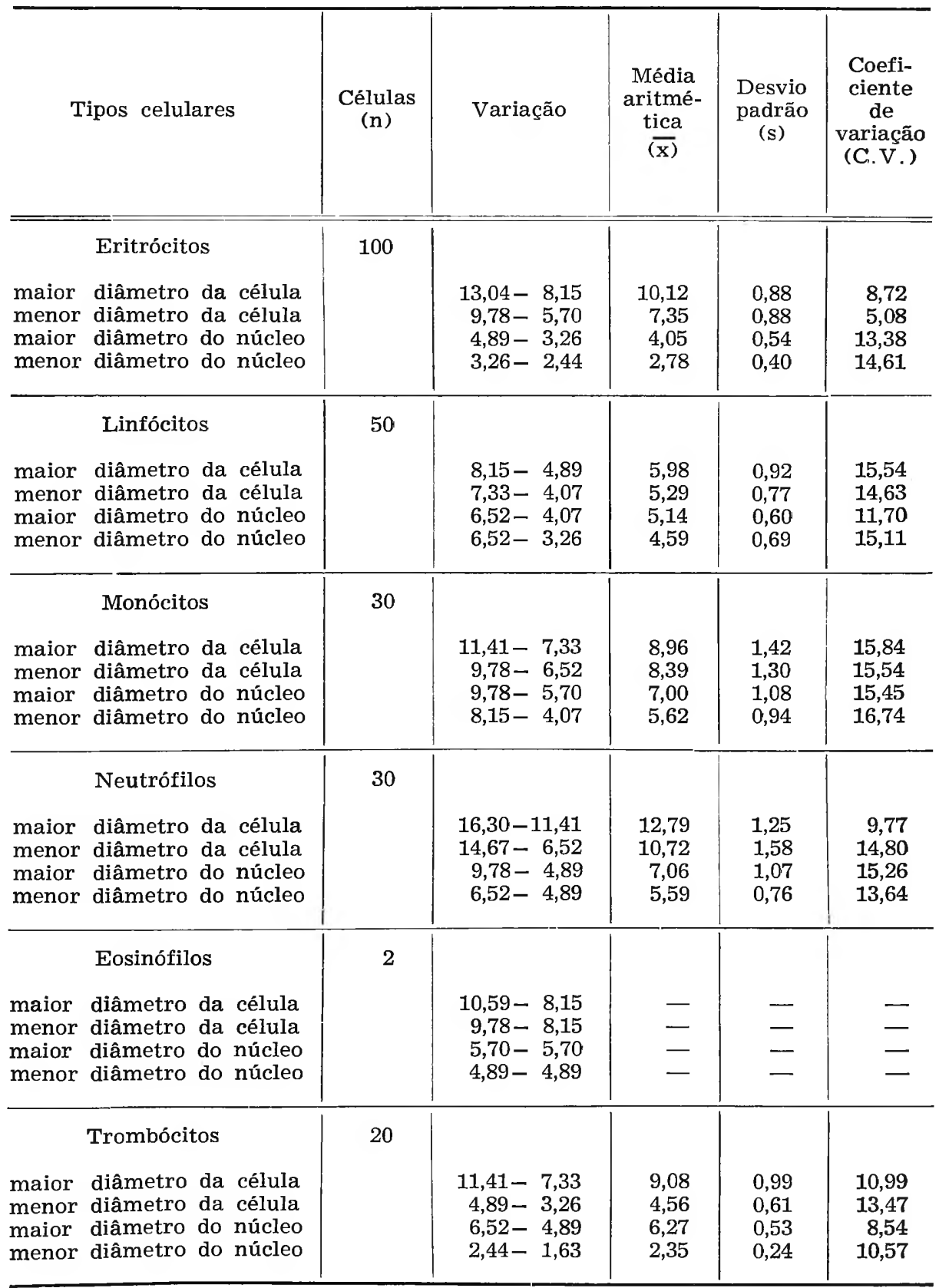




\section{DISCUSSÃO E CONCLUSÕES}

Comparando nossos dados com aqueles obtidos por Engel \& Davis (1964), para a cavala que habita a costa atlântica dos Estados Unidos da América, verifica-se que o número de eritrócitos é basicamente o mesmo, enquanto a dosagem da hemoglobina mostrou valores um pouco mais elevados no nordeste brasileiro, uma vez que esses autores registram a variação de 7,3 a 10,3, com a média de $9,30 \mathrm{~g} \%$.

Os resultados de eritrócitos, hemoglobina e hematócrito da cavala do nordeste brasileiro são bastante semelhantes àqueles encontrados para a serra, Scomberomorus maculatus (Mitchill), na mesma área (Bastos, 1966; Pitombeira \& Martins, 1970) e na costa atlântica dos Estados Unidos da América (Engel \& Davis, 1964).

Nos peixes marinhos, os valores de eritrócitos e hemoglobina no sangue, podem ser considerados como índices de atividade fisiológica, sendo mais elevados nas espécies de vida pelágica (Hall \& Gray, 1929; Engel \& Davis, 1964; Eisler, 1965; Gelineo, 1969). Em várias espécies de peixes marinhos, foi encontrada correlação positiva entre os valores da hemoglobina e as unidades respiratórias das brânquias (Gray, 1946). Tais fatos justificam a existência de um sistema vascular cutâneo mais desenvolvido nos peixes pelágicos (Klawe \& Barret, 1963).

A cavala é um peixe pelágico costeiro, muito ativo, estando incluído no grupo das espécies que requerem maior quantidade de oxigênio, para suas trocas metabólicas.

Os dados hematológicos da cavala, aqui apresentados, correspondem a indivíduos com até 5 anos de vida (Nomura \& Rodrigues, 1967), portanto em sua maioria imaturos (Ivo, 1972). Sendo assim, é de se esperarem valores mais altos de eritrócitos e hemoglobina para as cavalas maduras, quando aumentam suas necessidades metabólicas, decorrentes do início de ciclos de reprodução, com a simultânea intensificação de suas migrações.

O número de leucócitos da cavala, com valor médio de 31.390/ $\mathrm{mm}^{3}$ é semelhante ao registrado para a serra $\left(37.891 / \mathrm{mm}^{3}\right)$, das águas costeiras do nordeste brasileiro (Pitombeira \& Martins, 1970).

Os peixes apresentam, normalmente, um número elevado de leucócitos, quando comparados com outros animais (Jordan, 1938). Condições fisiológicas como a alimentação (Smirnova, 1965), ou patológi- 
cas como as infecções (Dombrowski, 1953) ou doenças do próprio sangue (Martins \& Pitombeira, 1968), têm determinado elevação do número de leucócitos.

Com respeito às cavalas’ estudadas, apenas podemos informar que elas estavam em estado hígido, considerando que nenhuma alteração morfológica dos leucócitos foi observada, o que é comum nos quadros patológicos (Katz, 1950).

Sendo o habitat da cavala mais afastado da costa, ela está menos sujeita à influência da poluição, comum nas águas litorâneas, em frente a grandes concentrações urbanas.

Não encontramos no sangue da cavala leucócitos basófilos, os quais foram observados na serra, enquanto que o corportamento dos leucócitos e trombócitos não diferiu do encontrado nesta espécie por último referida (Pitombeira \& Martins, 1970).

\section{AGRADECIMENTOS}

Expressamos os nossos mais sinceros agradecimentos ao senhor José Oliveira Pires, auxiliar técnico do Laboratório de Ciências do Mar da Universidade Federal do Ceará, pelas coletas das amostras de sangue da cavala, a bordo de pequenas embarcações de pesca, nos próprios locais de captura dos peixes.

\section{BIBLIOGRAFIA}

BARRET, I. \& WILLIAMS, A. A. (1965) - Hemoglobin content of the blood of fifteen species of marine fishes. Calif. Fish Game, 15(3):216-218.

BASTOS, J. R. (1966) - Sôbre a série vermelha do sangue de Scomberomorus maculatus (Mitchill). Arq. Est. Biol. Mar. Univ. Fed. Ceará, 6(1) :39-45.

CERVIGóN, F. (1966) - Los peces marinos de Venezuela. Est. Inv. Mar. Margarita, Fundación La Salle de Ciencias Naturales, II:439-951, Caracas.

EISLER, R. (1965) - Erythrocyte counts and hemoglobin content in nine species of marine teleosts. Chesapeake Science, 6(2):119-120.

ENGEL, D. W. \& DAVIS, E. M. (1964) - Relationship between activity and blood composition in certain marine teleosts. Copeia, (3):586-587.

GELINEO, S. (1969) - Haemoglobinkonzentration im blut der fische. Bull. Acad. Serbe Sci. Math. Nat., 12:25-67.

GERASINTCHIK, S. I. \& JAROV, V. L. (1969) - Soderjania gemoglobina v Krovi tuntsov i nekotorikh drugikh skombroidnikh rib Atlanticheskege okeana. Tuntsu $i$ drugie objekti tuntsovoge promisla, XXV:109-114.

GRAY, I. E. (1946) - The relations between gill surface and activity in marine fishes. Anat. Rec., 96(4):518. 
GUTIERRREZ, M. (1967) - Estudios hematológicos en el atún, Thunnus thynnus (L.), de la costa sudatlántica de España. Invest. Pesq., 31(1):53-90.

HALL, F. G. \& GRAY, I. E. (1929) - The hemoglobin concentration of the blood of marine fishes. J. biol. Chem., 81(3):589-594.

HAYHOE, F. G. J.; QUAGLINO, D. \& DOLL, R. (1964) - The citclogy and citochemistry of Acute Leukaemias. Her Majesty's Stationery Office, 150 pp., London.

IVO, C. T. C. (1972) - Época de desova e idade na primeira maturação sexual da cavala, Scomberomorus cavalla (Cuvier), no Estado do Ceará. Arq. Ciên. Mar., 12(1):27-29.

JORDAN, H. E. (1938) - Comparative Hematology. In DOWNEY, H. Handbook of Hematology. Paul Hoeber Inc., 2:703-862, New York.

KATZ, M. (1950) - Some interesting cells in the blood of a diseased Silver Salmon Fingerling. Copeia, (4):295-298.

KLA'WE, W. L.; BARRET, I. \& KLAWE, B. M. H. (1963) - Haemoglobin content of the blood of six species of scombroid fishes. Nature, 198(4875):96.

KORJUEV, P. A. \& GLAZOVA, T. N. (1968) - Sravnitelno - fiziologitcheskaia Kharakteristika Krovi i Krovotvornikh organov rib i vodnikh mlekopitaiushtshikh. Biologia moria., 15:131-146.

MARTINS, J. M. \& PITOMBEIRA, M. S. (1968) - High leukocyte count in fishes. Rev. Bras. Pesq. Med. Biol., 1(2):89-92.

McMANUS, J. F. A. (1946) - Histological demonstration of mucin after periodic acid. Nature, 158:202-205.

NOMURA, H. \& RODRIGUES, M. S. S. (1967) - Biological notes on king mackerel, Scomberomorus cavalla (Cuvier), from northeastern Brazil. Arq. Est. Biol. Mar. Univ. Fed. Ceará, y(1):79-85.

PITOMBEIRA, M. S.; BARRETO GOMES, F. V. \& MARTINS, J. M. (1969) - Hematological data on the fishes of the genus Mugil Linnaeus. Arq. Ciên. Mar., 9(2):163-166.

PITOMBEIRA, M. S. \& MARTINS, J. M. (1966) - A direct method for white blood cell count in fishes. Arq. Est. Biol. Mar. Univ. Fed. Ceará, 6(2):205.

PITOMBEIRA, M. S. \& MARTINS, J. M. (1970) - Hematology of the Spanish mackerel, Scomberomorus maculatus (Mitchill). Copeia, (1):182-186.

SCHAEFER, H. (1961) - Methodik und Ergebnisse von Untersuchungen der Erythrozyten und Hämoglobingehaltes frischgefange ner Seefische. Helgoländer Wissenschaftliche Meeresuntarsuchungen, 8(1):68-83.

SMIRNOVA, L. I. (1965) - Izmenenie Kartini Krovi u rib pri pishtshevarenii. Vop. Ikhtiol., $\mathbf{5}(1): 149-156$.

WINTROBE, M. (1933) - Variations in the size and hemoglobin content of erythrocytes in the blood of various vertebrates. Folia Haematol., 51:32. 
Este trabalho foi composto e impresso nas oflcinas gráficas da

coAnES TIPOGRAFIA EDANEE S.A.

à Rua do Bosque n.o 1.426 - São Paulo 
